\title{
CITRA TUBUH PEREMPUAN DALAM LUKISAN KARYA LUNA DIAN SETYA
}

\author{
Nanang Yulianto ${ }^{1}$, Ning Yuliastuti ${ }^{2}$ \\ ${ }^{1,2}$ Pendidikan Seni Rupa FKIP Universitas Sebelas Maret \\ nanangfirel@yahoo.co.id ${ }^{1}$, ningyuliastuti 2010@gmail.com ${ }^{2}$
}

\begin{abstract}
Female as subject matter in art perceived in various discourse. One of the subject that keeps surfacing is female body, somehow the subject magnetized painters, especially males, to explore its intriguity. But it is a different perspective from female painters when female body is used as an object inspiration for visual arts. Luna Dian Setya is one example of female painters in Surakarta who present female body in her paintings. This research explores; (1) what inspires Luna Dian Setya to construct images of female body in her hart?; (2) what kind of female body experience that Luna Dian Setya conveys in her art? Based on those two questions, Luna Dian Setya appears to explore the idea of myth and legends in female body as an instrument to surface her ideas and draw relevance of her artistic approach. The research also used the theory of imaging and imagery to contest male domination in visual art which more likely to present female body as exotic, erotic and vulgar commodity rather than its fotmality. Luna Dian Setya express more of a motherly nature, feminine and delicate aspect of female visualization.
\end{abstract}

Key words: image, female body, painting, art

\begin{abstract}
ABSTRAK : Subject matters perempuan dalam karya seni lukis terus hadir dalam wacana yang berbeda-beda, wacana yang satu melengkapi dan menguatkan wacana yang lainnya. Tubuh perempuan dalam beragam citra bagaikan magnet yang mendorong pelukis untuk terus menghadirkannya dalam lukisan yang dihasilkannya. Perspektif pelukis laki-laki dan perempuan tentunya berbeda pada saat mengkonstrksi citra perempuan yang diekpose dalam lukisannya. Luna dian Setya merupakan salah satu pelukis perempuan di Surakarta yang terus menghadirkan tubuh perempuan dalam lukisannya dengan beragam citra. Bertolak dari paparan tersebut maka dapat dirumuskan permasalahan penelitian sebagai berikut; 1) Apa yang menjadi latar belakang Luna Dian Setya dalam mengkonstruksi citra tubuh perempuan dalam lukisan?; 2) Citra tubuh perempuan bagaimana yang dihadirkan Luna Dian Setya pada lukisan. Berpijak pada permaasalahan tersebut, penulis menggunakan teori citra untuk mengungkap berbagai citra perempuan yang dihadirkan Luna Dian Setya. Berdasarkan hasil penelitian dan pembahasan dapat dikemukakan bahwa keinginan Luna Dian Setya dalam menghadirkan tubuh perempuan pada lukisan didorong keinginan untuk mengkontekstualkan berbagai nilai kehidupan dalam cerita rakyat agar relevan dengan semangat jaman sekarang, serta upaya untuk melakukan resistensi dominasi para pelukis laki-laki yang mengangkat tubuh perempuan pada lukisan dalam citra erotis, vulgar dan sensual. Luna Dian Setya pada lukisannya menghadirkan tubuh perempuan yang bercitra keibuan, penyabar, tenang, lembut, penuh kasih sayang.
\end{abstract}

Kata kunci: citra, tubuh perempuan, lukisan, seni

\section{Pendahuluan}

Praktek kesenirupaan sebagai ekspresi dan respon sosial waktu ke waktu telah mencatatkan sejarahnya. Respon sosial terhadap realitas juga tidak luput menempatkan sosok perempuan sebagai kajian penting untuk terus diwacanakan. Tidak hanya karena tubuh perempuan mempunyai multi sensasional, artinya tidak hanya sensasi artistik. Namun sensasi sosial menempati wacana yang sangat menarik untuk terus direspon oleh seniman, dalam hal ini juga tidak luput dari bidikan kuas para pelukis.

Seni rupa dan perempuan memiliki kaitan erat, baik perempuan sebagai subjek yaitu sebagai sabjek meter, tema, atau pesan moral yang dapat digali secara mendalam, sementara perempuan sebagai objek seni, adalah menempilkan sosok perempuan 
dalam berbagai figur, secara realistik hingga yang bersifat abstraksi. Kondisi tersebut sudah menjadi realitas yang tidak terbantahkan. Semua orang telah dibuktikan, semakin banyak para perupa, termasuk para perempuan dengan berbagai karya yang terus mewacanakan perempuan dalam berbagai sudut pandang.

Penegasan tentang hadirnya perupa perempuan dilontarkan oleh kolektor seni rupa Indonesia bernama Djien (2012:256) Perempuan adalah subject matter yang paling menarik, dikarenakan perempuan menggoda untuk dianalisis, dipelajari, dirasakan, digarap dan diekspresikan dalam berbagai bentuk karya seni. Perempuan makhluk yang kompleks dan mengandung banyak misteri. Demikian juga Winarno (2015:98) menyatakan bahwa visualisasi tubuh perempuan menjadi visual yang digemari oleh para perupa di dunia, karena apresiator di setiap era menyukai visualisasi tersebut. Sebuah mata rantai yang tak terputus.

Kehadiran sosok perempuan dalam karya seni rupa bisa menjadi daya tarik, namun disisi yang lain dapat mendatangkan polemik dengan berbagai alasan. Siregar (2015:54-56) menyatakan objen perempuan dalam seni rupa jika ditinjau dalam sejarah seni rupa pada umumnya. Objek tubuh perempuan telah banyak dicatat, bahwa kehadiran tubuh pada karya seni telah beberapa kali ditakhlukkan dengan protes dan sensor. Protes tersebut berhubungan dengan konteks pornografi yang selalu menyisakan perdebatan tiada akhir. Karya instalasi Agus Suwage berjudul Pink Swing Park pada pameran CP Biennale Internasional Museum Bank Indonesia akibat tuntutan Front Pembela Islam (FPI) pada tahun 2005. Terjadinya pro dan kontra terhadap tubuh perempuan dalam karya seni rupa justru menjadikan tubuh perempuan sebagai magnet atau daya tarik yang semakin kuat dalam kehadiran karya seni rupa.

Kegairahan dalam mengeksplor tubuh perempuan dipraktikkan oleh para pelukis di seluruh dunia, tak terkecuali pelukis di Surakarta. Hal ini dapat dilacak pada lukisan karya Dullah, Hasyim K, Kawit T, Hery Soedjarwanto, Wiryono, dan yang lainnya. Disamping para pelukis laki-laki, ada juga pelukis perempuan yang terus memperbincangkan tubuh perempuan melalui karya-karyanya, salah satunya Luna Dian Setya. Luna secara intens terus mencoba mengemukakan gagasannya tentang perempuan kekinian yang dihadapkan pada budaya populer.

Luna Dian Setya sebagai pelukis muda yang dihadapkan pada praktik kehidupan budaya populer di Surakarta senantiasa membangun pandangan dan ideologi berkeseniannya. Ia senantiasa kritis terhadap sosok perempuan, mengingat ia sendiri juga perempuan yang hidup dengan berbagai persoalannya. Luna melalui karyanya terus mengangkat problematika perempuan yang kontekstual agar tidak kehilangan spirit zamannya. Ketika pelukis perempuan mengemukakan persoalan tubuh perempuan, tentun cara dan pandangan yang dilakukan oleh perupa perempuan tentu berbeda dengan perupa laki-laki. Perbedaan perspektif itu apabila dibandingkan tentu akan menjadi daya tarik tersendiri, Hal ini dapat dihayati, sebenarnya pikiran dan pandangan laki-laki dalam mengekspresikan tubuh perempuan, gairah, seksualitas, kekaguman, atau obsesi yang tidak dapat diungkapkan secara verbal. Namun apakah demikian juga jika perupa perempuan dalam mengekspresikan tubuh perempuan. Perempuan tentu menggali apa yang disebut sebagai perempuan, tubuh mungkin dapat ditampilkan sebagai sosoak yang tidak memiliki perbedaan. Namun perempuan mendalami keperempuannya, sudah dapat dipastikan memiliki perbedaan.

\section{Metode}

Penelitian eksploratif ini dilakukan di studio lukis Luna Dian Setya. Tepatnya stodio itu berada Jl. Jayawijaya 55 Mojosongo Jebres Surakarta. Waktu melakukan eksploratif sekitar bulan mei juli 2018. Penuangan penulisan penelitian menggunakan deskriptif kualitatif, artinya meungkapkan secara verbal dan menuangkan secara naratif sesuatu yang dapat ditangkap melalui panca indra. Strategi penelitian bersifat studi kasus. Sutopo (2002: 12) menguraikan bahwa penelitian terpancang merupakan suatu 
langkah sebelum melakukan penelitian harus memilih dan menentukan variabel yang menjadi fokus utamanya namun tetap terbuka dengan sifat interaktif dan fleksibel utamanya. Sumber data berupa: a) Informan, baik sebagai narasumber yang dapat digali pemikiran, gagasan, dan asumsi-asumsi melalui pertanyaan-pertanyaan, selain itu juga menetapkan pengamatan langsung tentang; b) Tempat dan Peristiwa, peneliti melakukan pengamatan yang menempatkan subjek terteliti dalam ranah raang, dalam hal ini tempat dimana seorang seniman berkerja, dan proses kreatif adalah sebuah proses potensial dalam mengekspresikan diri, c) arsip/dokumen. Peneliti juga menggunakan data yang berupa catatan, foto-foto, atau tulisan-tulisan yang terkait dengan aktivita pelukis dan atau tentang karya-karyanya. Peneliti yang memforkuskan pada kerja seorang pelukis dan lukisannya, tentunya hal ini tidak terkait dengan persoalan yang lain, oleh karena itu peneliti menggunakan teknik sampling yang menggunakan purposive sampling, sampelnya bersifat tunggal dan telah ditentukan secara pasti. Teknik pengumpulan data menggunakan: a) observasi dan b) wawancara mendalam, c) analisis isi dokumen/arsip. Validitas Data menggunakan: a) triangulasi sumber, b) review informan. Analisis Data menggunakan model interaktif yang terdiri dari tiga komponen, yaitu: reduksi data, artinya peneliti mempertimbangkan atas dasar pilihan tertentu untuk menggunakan data yang sesuai dan pasti terkait dengan rancangan atau pertanyaan penelitian. Adapun penyajian data disajikan secara diskriptif verbalistik, dan setelah semua dapat disajikan melalui pertimbangan analitis, kemudian diakhir dengan penarikan kesimpulan.

\section{Paparan Data Dan Hasil 1.Paparan Data}

Setiap proses kreatif penciptaan karya seni lukis yang dilandasi oleh kaidah akademik, pada dasarnya dilandasi oleh konsep yang menjadi latar belakang. Adapun latar belakang Luna sebagai seorang perupa dalam menghadirkan subject matters tubuh perempuan pada setiap lukisannya dapat dicermati sebagai berikut: a. Menggali Spirit dan Citra Tokoh Calon Arang Untuk Disesuaikan dengan Konteks Kehidupan Sekarang

Luna menempatkan dirinya sebagai pelukis yang berdomisili di Surakarta, sebuah kota yang memiliki latar belakang historis. Kota yang bersejarah itu tentu menyimpan berbagai prolematika yang sangat kaya terhadap aspek kehidupan, bahkan kota tua itu memiliki keterikatan dengan budaya nenek moyang, khususnya budaya Jawa. Surakata sebagai pusat kebudayaan masa lalu itu banyak di sebutsebut dalam berbagai teks.

Teks-teks budaya yang ditampilkan dari masa-kemasa berupa cerita rakyat (foklur). Cerita yang tumbuh dalam latar kehidupan sosial yang menyimpan berbagai hal, baik yang terkait dengan kesejarahan atau terkait dengan peristiwa alam. Teks tersebut telah banyak yang ia kaji sebagai media untuk mengkonstruksi pemahaman dan perenungan. Sebagai perupa yang berada dalam lingkungan masyarakat etnik, banyak cerita rakyat yang menjadi perhatian. Salah satu cerita rakyat yang pernah mengusik pekiran pelukis itu adalah cerita dari masa kerajaan besar di Jawa Timur, yaitu cerita tentang Calon Arang.

Cerita Calon Arang adalah sebuah cerita rakyat yang berlatar belakang dendam dan asmara. Cerita ini bermula dari kisah seorang perempuan yang sudah tidak bersuami (janda), dia bertahun-tahun mempelajadi ilmu hitam. Ilmunya seringkali dicoba untuk membuat penduduk menjadi resah, janda itu sering merusak hasil panen para petani dan sehinga menyebabkan datangnya wabah penyakit, istilah Jawa bagebluk. Janda yang bermukim di desa Dirah itu mempunyai seorang puteri yang sangat cantik jelita, gadis itu bernama Ratna Manggali. Dikisahkan, Retna Manggali yang cantik itu tidak dapat mendapatkan seorang suami, karena orang-orang takut pada ibunya yang dikenal sebagai dukun sakit mandraguna.

Calon Arang merasa bersalah dan selalu gelisah atas nasib sial putrinya, berbagai upaya telah dilakukan untuk mengatasi kesulitan yang dihadapi puterinya, Calon Arang dengan menggunakan ilmu hitamnya untuk 
menculik seorang gadis muda dari beberapa desa. Gadis gadis-gadis yang diculik itu kemudian dibawa ke sebuah kuil pamujan, kemudian dilakukan sebuah upacara korban yang dipersembahkan kepada Dewi Durga. Pada hari berikutnya, terjadi bencana banjir besar melanda desa tersebut dan banyak orang meninggal dunia. Penyakit pun muncul tek henti-henti. Sehingga membuat kegelisahana semua masyarakat, bahkan hingga terdengar ke pusat pemerintahana di Kahuripan.

Raja Erlangga mengetahui peristiwa yang menggemparkan itu, kemudian mengutus seorang pendeta kerajaan untuk mengatasi peristiwa yang membuat masyarakat menderita itu. Pendeta yang dikenal dengan nama Empu Baradah itu kemudian bertindak, dia berjanji untuk mengatasi masalah yang terjadi. Empu Baradah kemudian mengirimkan seorang muridnya bernama Empu Bahula, seorang pemuda tampan dan cerdas. Bahula disuruh menyamar agar dapat menikah dengan Ratna Manggali. Setelah keduanya berhasil dinikahkan, bahkan dibuat pesta pernikahan secara besar-besaran selama tujuh hari tujuh malam. Berbagai hiduran dan kesenian didatangkan, semua masyarakat diundang untuk makan minum sepuasnya. Atas pernikahan tersebut kondisi di desa Dirah menjadi kembali normal, aman dan tentram. Bahula dan Ratna Manggali hidup berbahagia.

Namun misi Bahula tidak cukup sampiai di situ, pesan gurunya Empu Barada, dia harus dapat menemukan kelemahana Calon Arang. Setelah dipelajari dalam waktu yang cukup lama, ternyata Calon Arang mempunyai sebuah buku sakit, buku itu berisi ilmu-ilmu sihir. Pada suatu hari, buku ini berhasil ditemukan oleh Bahula yang menyerahkannya kepada Empu Baradah.

Pada saat tertentu, Calon Arang mengetahu bahwa bukunya telah dicuri oleh menantunya, ia menjadi marah dan memutuskan untuk melawan Empu Baradah. Calon Arang kembali memuja Dewi Durga dan dengan semangat kemarahana yang membara, Calon Arang menantang $\mathrm{Mpu}$
Barada. Namun nasib telah digariskan, Calon Arang yang sangat mencintai putrinya itu harus dikalahkan oleh laki-laki yang bernama Baradha.

Calon Arang merupakan salah satu cerita rakyat yang menarik bagi Luna untuk diangkat dalam karya seni lukis. Tokoh Calon Arang menjadi subject matters dalam beberapa karyanya, yang dihadirkan tidak secara tekstual namun kontekstual dengan spirit hidup kekinian.

Kemampuan atau daya kritis yang dimiliki Luna digunakan untuk mengkritisi dan mengkontekstualkan tokoh-tokoh perempuan dalam cerita Calon Arang dengan tujuan agar tidak menjadi teks beku dan berhenti pada spirit masa lalu. Dalam perspektif Luna, nilai-nilai kehidupan yang universal pada dasarnya bisa dibangun dan hadir dalam diri setiap manusia tanpa memandang perbedaan gender. Dalam diri seorang perempuan tidak mesti hadir nilainilai penakut, lemah lembut, sabar, dll, namun bisa juga hadir nilai perkasa, kokoh, tegas dan lain sebagainnya.

Luna melalui visualisasi perempuan ingin meneguhkan keyakinannya bahwa nilai dan citra diri seorang perempuan bukan bersifat stereotipe, namun dinamis. Perempuan bisa menjadi sosok yang kadang kejam kadang penyayang, kadang lemah kadang tegas. Konsekwensi dari pandangan tersebut menjadikan visualisasi Calon Arang dalam lukisan seolah-olah menjadi tokoh yang lain, yaitu tokoh yang merupakan impian Luna. Luna berusaha mengkontekstualkan nilai dan citra diri Calon Arang yang masih relevan dengan kehidupan kekinian.

b. Perlawanan Terhadap Kecenderungan Visual Perempuan Dalam Lukisan yang Menempatkan Tubuh Bercitra Sensual, Erotis dan Vulgar

Luna banyak menemukan lukisanlukisan yang mengangkat subject matters perempuan dengan beragam citra. Adanya dominasi pelukis laki-laki atas tubuh perempuan, banyak yang menempatkan tubuh perempuan dalam citra sensual, erotis, vulgar. Luna dalam hati kecilnya ingin protes, meskipun tidak secara terang- 
terangan. Perlawanan yang dilakukan Luna dilakukan dengan menghadirkan citra diri perempuan yang lain, sebagai upaya untuk menempatkan perempuan di tempat yang terhormat dan sejajar dengan kaum laki-laki.

Perlawanan yang dilakuukan Luna dengan cara melukis sosok atau tubuh perempuan dengan penggarapan gesture atau ekspresi tubuh yang menjauh dari kesan sensual, erotis, vulgar. Ia mengkonstruksi tubuh perempuan kedalam citra yang penuh kasih, sabar dan penyabar. Tubuh perempuan merupakan objek penting dalam lukisan-lukisan Luna, tubuh perempuan tidak dihadirkan dalam artian fisik semata yang menjebakkan diri pada citra sensual dan vulgar, namun tubuh yang dibingkai dalam nilai spiritualitas. Salah satu penanda yang menguatkan adanya citra spiritualitas adalah visualisasi alam dengan segala pernak-pernik didalamnya yang diharapkan mampu menggiring apresian pada citra kehidupan secara luas. Perempuan adalah bagian penting kehidupan itu sendiri, ia tidak bisa terpisahkan dengan unsur alam yang lain, sehingga menjadikan kehidupan menjadi indah, menarik dan bergairah.

\section{c. Citra Tubuh Perempuan Dalam Lukisan Luna}

Berpijak pada beberapa visualisasi lukisan yang dihasilkan Luna Dian Setya, maka citra dan representasi tubuh perempuan dapat dipaparkan sebagai berikut:

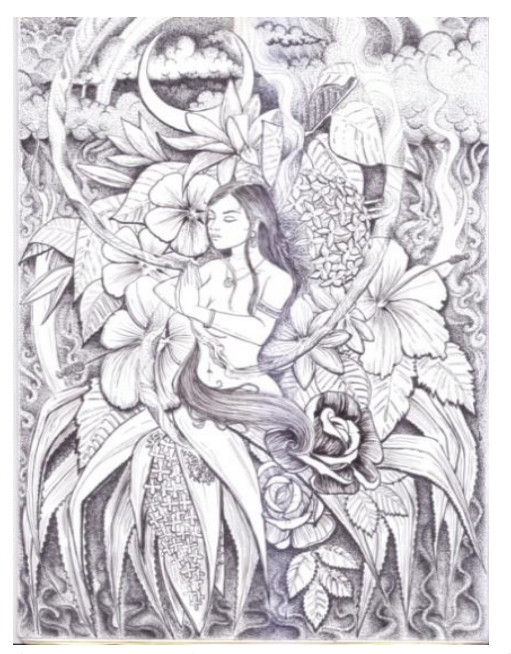

Gambar 1. Kembang Pasetran, Drawing

Pen Diatas Kertas, 2017, 40 x 30 cm

Visualisasi lukisan berupa sosok perempuan muda dengan rambut terurai panjang, menyatukan kedua tangannya didepan dada, dikelilingi rumpun tanaman dan bunga, tidak menggunakan pakaian, menutup kedua matanya. Representasi lukisan berupa Calon Arang yang sedang bermeditasi di alam, menjauhkan diri dari hiruk pikuk aktivitas kehidupan manusia. Pilihan tempat bermeditasi di alam terbuka memberikan kesan bahwa perempun tersebut tidak ingin berjarak dengan alam dan kehidupan. Meditasi sebagai aktivitas jiwa merupakan aktivitas yang penting untuk menyuburkan dan menyucikan jiwa, karena segala sikap dan perbuatan manusia bersumber dari kesucian jiwa.

Citra perempuan yang dihadirkan dalam lukisan berupa perempuan dengan hati dan jiwa yang bersih, tenang, hening, hormat dan berpasrah pada alam dan Tuhan yang memilikinya. Ketelanjangan perempuan yang bermeditasi sebagai upaya untuk menyatukan dirinya yang murni/apa adanya dengan alam yang apa adanya juga. Citra perempuan bersinergi dengan citra alam dalam menguatkan hadirnya citra tubuh perempuan yang senantiasa hormat pada alam dan kehidupan. 


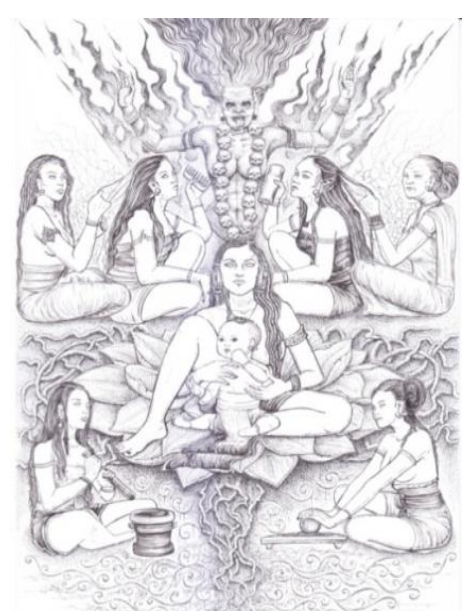

Picture 2. Madonna of Girah, Drawing Pen Diatas Kertas, 2017, 40 x $30 \mathrm{~cm}$

Madonna dalam Oxford Dictionaries bermakna perempuan terhormat, saleh dan keibuan. "Madonna of Girah" dimaksudkan sebagai perempuan terhormat, saleh dan keibuan dari Desa Girah. Visualisasi lukisan berupa sosok perempuan duduk diatas bunga tunjung dengan anaknya diantara beberapa perempuan. Perempuan-perempuan tersebut sedang melakukan kegiatan sehari-hari seperti menghaluskan bahan makanan, menata rambut, mengurus anak dan bersosialisasi dengan teman-teman. Di belakang perempuan yang duduk di tengah bunga tunjung, ada bayangan sosok raksasa perempuan berwajah tua dan berkalung tengkorak manusia.

Lukisan merepresentasikan Calon Arang bagaikan ratu tanpa mahkota, tanpa singgasana, menjadi pemimpin, seorang ibu untuk anak kandungnya dan perempuan lain yang lebih muda. Calon Arang mendapat restu dari ibu spiritualnya dan memiliki kedewasaan mental yang jauh lebih tua dari usia sesungguhnya. Calon Arang menjadi penjaga keseimbangan antara kiri dan kanan.

Citra perempuan yang dihadirkan berupa perempuan yang memiliki rasa kasih sayang, keibuan, penyabar, penyayang, menghormat dan menghargai terhadap sesama. Citra perempuan yang mampu menerapkan nilai-nilai kedamaian dan ketenangan hidup baik sebagai makhluk sosial maupun spiritual.

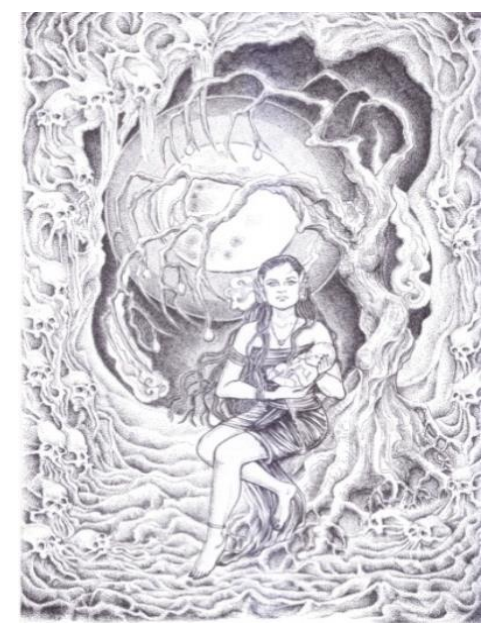

Picture 3. Biyung Agung, Drawing Pen

Diatas Kertas, 2017, 40 × $30 \mathrm{~cm}$

Visualisasi lukisan berupa sosok perempuan berambut panjang yang duduk diatas batang pohon dengan bayinya dibawah sinar bulan purnama. Latar belakang lukisan berupa pohon dengan akarakar yang menjuntai dan tengkorak yang berada di atas, samping, belakang dan bawah perempuan. Representasi lukisan menggambarkan Calon Arang dengan sikap kedewasaan dan keibuannya. Ia hidup dalam kesunyian, dan dalam suasana sunyi itulah ia menemukan pemahaman dari apa yang telah dijalani dan dipelajarinya. Bagi Calon Arang menjadi seorang ibu merupakan kesempurnaan bagi perempuan, dan merupakan fase puncak dari perjalanan hidup seorang wanita. Pandangan tersebut diperkuat dengan visualisasi bulan purnama sebagai simbol hidup yang cerah dan sempurna.

Citra perempuan yang hadir pada lukisan tersebut berupa perempuan yang penuh kasih sayang, kehati-hatian, damai, tenang dan pemberani.

\section{Pembahasan}

Luna Dian Setya sebagai pelukis perempuan memiliki motivasi yang kuat untuk mengangkat nilai-nilai kehidupan yang tersembunyi dalam diri perempuan melalui lukisan yang dihasilkannya. Perempuan yang selama ini distereotipkan oleh sebagian besar pelukis laki-laki dalam citra sensual, vulgar dan erotis, ia coba mengemukakan nilai-nilai lain seperti kasih 
sayang, keibuan, penyabar, tenang, lembut, hening, pemberani dan berpasrah.

Sikap ini dilatarbelakangi oleh semakin menguatnya daya kritis yang dimiliki Luna, yang mana ia senatiasa tidak ingin melihat segala sesuatu berdsarkan kehadiran fisik semata, namun berusaha untuk menggali apa yang ada di balik kehadiran fisik tersebut. Keberadaan lingkungan sosial budaya yang dijalani Luna semakin menguatkan pentingnya menyuarakan suara hatinya secara jujur berlandaskan keykinan dan pandanganpandangan pribadinya.

Luna sadar bahwasanya didalam diri perempuan berbagai citra bisa hadir dan dikonstruksi, semua kembali bergantung pada diri manusia citra mana yang akan diserapnya. Budaya populer yang berkembang saat ini dengan menyodorkan nilai-nilai permukaan, kesesaatan, berbanding terbalik dengan apa yang telah disodorkan Luna melalui lukisannya. Meski dalam kehidupan sehari-hari Luna mengamati bagaimana perempuan sekarang yang sudah cukup banyak terjebak dalam praktik budaya populer, namun ia tetap optimis dalam menyampaikan citra perempuan yang ia impikan dan yakini. Ia tanpa lelah dan percaya diri terus menggali dan mengemukakan citra perempuan yang bertolak belakang dengan prinsip budaya populer.

Keberanian dalam melakukan perlawanan terhadap dominasi budaya populer saat ini menjadikan lukisan Luna sebagai obat dahaga atas kegersangan nilainilai ke"perempuan"an dalam seni lukis saat ini. Luna dan lukisan-lukisannya tidak begitu larut dalam arus budaya populer yang berusaha mengasingkan nilai-nilai kehidupan yang filosofis dan substantif kedalam kubangan budaya populer yang dangkal dan mengejar kesenangan visual semata.

\section{Simpulan}

Luna dalam melukis tubuh perempuan memiliki latar belakang dan motivasi yang jelas dan kontekstual dengan kehidupan saat ini. Latar belakang tersebut adalah keinginan Luna untuk mengangkat kembali nilai dan citra perempuan yang ada dalam cerita rakyat (Calon Arang) ke dalam konteks hidup saat ini, serta keinginannya untuk melakukan perlawanan terhadap dominasi lukisan-lukisan yang mengangkat tema perempuan kedalam citra yang erotis, vulgar, sensual. Perlawanan tersebut dilakukan dengan menghadirkan lukisanlukisan dengan citra perempuan yang berbeda, yaitu citra keibuan, kasih sayang, tenang, lembut, penyabar, pemberani, pasrah.

Sikap berkesenian Luna berusaha melakukan perlawanan terhadap dominasi budaya populer yang berus aha mengasingkan nilai-nilai filosofis kehidupan budaya Jawa khususnya yang telah diajarkan nenek moyang. Nilai-nilai tersebut harus senantiasa disemaikan dalam atmosfir budaya yang berkembang dalam kehidupan saat ini.

\section{DAFTAR PUSTAKA}

Djien, Oei Hong. 2012. Misteri Perempuan Tiada Habisnya Dalam Kumpulan Tulisan dr. Oei Hong Djien: Seni dan Mengoleksi Seni. Jakarta: Gramedia.

Damajanti, Irma. 2013. Psikologi Seni Sebuah Pengantar. Bandung: Kiblat Buku Utama

Jennong, Agung Hujatnika. 2006. AvantGardeisme Dalam Seni-Otonomi, Resistensi dan Sub-versi, Dalam Resisitensi Gaya Hidup: Teori dan Realitas. Yogyakarta: Jalasutra

Moleong, Lexy. 2010. Metodologi Penelitian Kualitatif. Bandung: Remaja Rosdakarya.

Pilliang, Yasraf Amir. 1998. Sebuah Dunia Yang Dilipat: Realitas Kebudayaaan Menjelang Milenium Ketiga dan Matinya Posmodernisme. Bandung: Mizan. 2004. Post-Realitas, Realitas Kebudayaan Dalam Era PostMetafisika. Yogyakarta: Jalasutra

Raditya, Adhie. 2014. Sosiologi Tubuh, Membentang Teori di Ranah Aplikasi. Yogyakarta: Kaukaba Dipantara 
Siregar, Aminuddin TH. 2015. Tubuh dan Sensor di Seni Rupa. Dalam Katalog Lakon Tubuh Chaosmos Perjalanan Jiwa Pameran Tunggal Setiawan Sabana di Bentara Budaya Jakarta.

Soetrisno, Mudji. 2006. Oase Estetis, Estetika Dalam Kata dan Sketsa. Yogyakarta: Kanisius

Strinati, Dominic. 2016. Popular Cultural, Pengantar Menuju Teori Budaya Populer. Yogyakarta: Narasi.

Sutopo. 2002. Metodologi Penelitian Kualitatif. Surakarta: Universitas Sebelas Maret.

Winarno, Ira Adriati. 2015. Tubuh Perempuan Sebuah Renungan
Dalam Karya Seni Rupa. Dalam Katalog Lakon Tubuh Chaosmos Perjalanan Jiwa Pameran Tunggal Setiawan Sabana di Bentara Budaya Jakarta

Zaelani, A Rizky. 2002. Persoalan (Atas Nama) High Art. Dalam Aspekaspek Seni Visual Indonesia: Identitas dan Budaya Massa. Yogyakarta: Yayasan Seni Cemeti.

Zainuddin, Imam Buchori. 2010. Wacana Desain, Karya dan Pemikiraan Imam Buchori Zainuddin. Bandung: Penerbit ITB 